\title{
A Small Structural Monetary Policy Model for Small Open Economies with Debt Accumulation
} Philippe Karam and Adrian Pagan 



\title{
IMF Working Paper
}

IMF Institute

\section{A Small Structural Monetary Policy Model for Small Open Economies with Debt Accumulation}

\author{
Prepared by Philippe Karam and Adrian Pagan ${ }^{1}$
}

Authorized for distribution by Ralph Chami

March 2008

\begin{abstract}
This working Paper should not be reported as representing the views of the IMF. The views expressed in this working Paper are those of the author(s) and do not necessarily represent those of the IMF or IMF policy. Working Papers describe research in progress by the author(s) and are published to elicit comments and to further debate..

We extend a small New Keynesian structural model used for monetary policy analysis to address a richer class of policy issues that arise in open economy analysis. We draw a distinction between absorption and domestic output, and as the difference between the two is effectively the current account, there is now an explicit accumulation or decumulation of foreign liabilities in response to various shocks affecting the system. Such stock equilibria can now have an impact back on to the flows in the domestic economy. We perform simulations using parameters calibrated to the Canadian economy and compare the differences in impulse responses from the original model. Advantages in a forecasting environment owing to the ability to impose explicit projections about imports and exports are also exposed.
\end{abstract}

JEL Classification Numbers: F41, E52, C51.

Keywords: Small open economy, monetary policy, model construction and estimation.

Author(s) E-Mail Address:pkaram@imf.org, a.pagan@qut.edu.au

\footnotetext{
${ }^{1}$ We would like to thank members of the 'Applied Economic Modeling Group' at the Fund for their encouragement in extending a prototype 'Monetary Policy Model' to deal with a richer class of policy issues that arise in open economy analysis. We thank Andrew Feltenstein and Doug Laxton for their valuable comments, and Yasmina Zinbi for her excellent assistance in formatting the paper.
} 


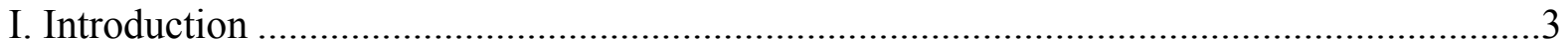

II. The Design of the BKL Model...............................................................................

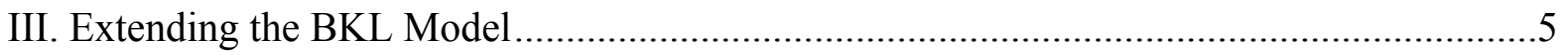

IV. An Illustration of the EBKL Model............................................................................ 11

A. Calibrating EBKL to the Canadian Economy ................................................ 11

B. Experiments with the Calibrated EBKL Model ................................................... 16

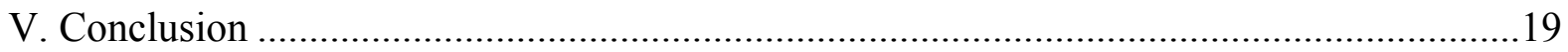

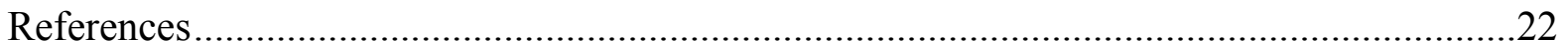

Tables

1. Structural Parameter Estimates for Canada ................................................................. 15

2. Parameter Values for Shocks .................................................................................. 15

3. Variances of Data and Model Variables ...................................................................... 15

Figures

1. Plot of GNE and GDP Gaps.................................................................................. 12

2. Average Growth Rate of Imports Less Long-Run Growth in GDP ...............................13

3. Average Growth Rate of Exports Less Long-Term ........................................................13

4. Plot of Export Regression Predictions Against US Ouput Gap Along with $1.5^{*}$ USGAP ... 14

5. Impact of Interest Rate Shock on GNE and GDP gaps ............................................. 16

6. Effects of Interest Rate Shock on Inflation with and without Risk Premium.....................17

7. Effects of Terms of Trade Shock on GDP gap with complete Foreign or Domestic

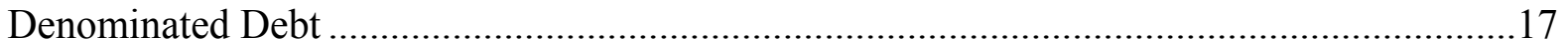

8. Effects on Debt Ratio of Terms of Trade Shock with Full Foreign or Domestically

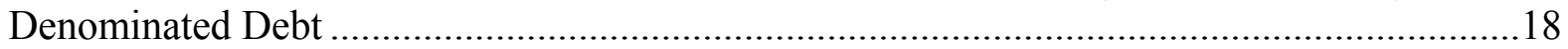

Appendix

EBKL versus the Stylized Equations 


\section{INTRODUCTION}

Berg, Karam and Laxton (2006) (BKL) document a small model that can be used for considering monetary policy actions and options in inflation targeting countries. The model, termed here the BKL model, is a vehicle for understanding and viewing policy options in a small open economy. It consists of two sets of equations. One describes the small economy under consideration and the other the "rest of the world", or at least that part of the world that is viewed as important for the economic outcomes of the small country. The model is loosely based upon the ideas that underline New Keynesian (NK) models of an open economy set out in papers such as Svensson (2000), and so its parameters are those associated with such models rather than coming from a precisely specified DSGE model. In many NK models the endogenous variables are expressed as a gap between the observed outcome and the equilibrium value for the variables. The BKL model features such 'gaps', so it is usefully thought of as being from the class of models which work with such a paradigm e.g. QPM from the Bank of Canada and FPS from the Reserve Bank of New Zealand.

An application of the model was provided to Canada involving the augmentation of the basic NK model with oil prices. This application involved calibrating the model parameters by reference to various pieces of evidence. The model has now been applied to a number of countries, such as the Czech Republic, Thailand, South Africa and Mexico. The application to those countries requires some re-calibration of the parameters of the basic model to reflect the structure and institutional features of those countries. Typically parameters are still calibrated but often they are chosen as being appropriate to that country based on the experiences of specialists working in the Central Bank or Finance Ministry.

In this paper we consider extending the model to enable one to address a richer class of policy issues that arise in open economy analysis and which may be particularly important in assessing the prospects of emerging economies. In performing the extension we wished to add on to BKL the minimal number of extra equations so as to preserve its simple structure. Accordingly, the extension has two dimensions. First, a distinction is made between absorption and domestic output. Second, as the difference between the latter two variables is effectively the current account, there is now an explicit accumulation or decumulation of foreign liabilities (in a flexible exchange rate system) to various shocks affecting the system. It seems likely that such stock disequilibria will have an impact back on to the flows in the domestic economy, and so one needs to account for such effects. Most work with small "gap" models such as BKL ignore the consequences of shocks for the stock of external debt and so the latter might conceivably accumulate without end. This is unlike the situation with DSGE models where the model is designed to eliminate such behavior. It seems worthwhile making such an adaptation to BKL as well. We will refer to the resulting model as the Extended BKL model (EBKL). 
In section 2 of the paper we briefly set out the BKL model. Section 3 then outlines our extension of it. Section 4 performs some simulations with EBKL using parameters calibrated to the Canadian economy in order to illustrate the differences that one would find if EBKL was adopted in place of BKL. Apart from possible differences in impulse responses due to a better integration of financial stocks and flows, there might be other advantages in a forecasting environment owing to the ability to impose explicit projections about imports and exports. This is often important given that trade flows often outpace GDP growth in countries that have engaged in economic reforms, so that trying to capture their movements with output gaps can be quite misleading.

\section{THE DESIGN OF THE BKL MODEL}

To assist the analysis it is useful to first work with a stylized version of BKL which is much closer to models that appear in the open-economy DSGE literature e.g. Nimark (2007). An inessential modification is that we will ignore the "rest of the world", as it is exogenous anyway. Since BKL simply treat the rest of the world as an economy that has the same structure as the domestic one it is also possible to do this if it is felt desirable. A more consequential adjustment is the removal of any special terms that come from items such as oil prices. These can be easily re-introduced later when matching data but, since they are exogenous to the small economy, they do not fundamentally change the analysis. We will also look at expectations and lag structures that are conventionally found in New Keynesian models so as to simplify the exposition, although in practice more general lag structures are possible.

There are four basic equations in BKL - an IS curve expressed in terms of an output gap, a Phillips curve describing inflation, an interest rate rule and a real uncovered interest parity (UIP) equation. ${ }^{2}$

$$
\begin{gathered}
\tilde{y}_{t}=\beta_{\text {lead }} E_{t}\left(\tilde{y}_{t+1}\right)+\beta_{\text {lag }} \tilde{y}_{t-1}-\beta_{r} \hat{r}_{t-1}-\beta_{z} \tilde{z}_{t-1}+\beta_{f} \tilde{y}_{t}^{*}+\psi_{y t}+\varepsilon_{t}^{y} \\
\hat{\pi}_{t}=\alpha_{\text {lead }} E_{t}\left(\hat{\pi}_{t+1}\right)+\left(1-\alpha_{\text {lead }}\right) \hat{\pi}_{t-1}+\alpha_{y} \tilde{y}_{t}-\alpha_{z} \Delta \tilde{z}_{t}+\psi_{\pi t}+\varepsilon_{t}^{\pi} \\
\hat{\imath}_{t}=\gamma_{\text {lag }} \hat{l}_{t-1}+\left(1-\gamma_{\text {lag }}\right)\left(\hat{r}_{t}+\hat{\pi}_{t}+\gamma_{\pi} E_{t} \hat{\pi}_{t+1}+\gamma_{y} \tilde{y}_{t}\right)+\psi_{i t}+\varepsilon_{t}^{i} \\
\tilde{z}_{t}=\delta_{z} E_{t}\left(\tilde{z}_{t+1}\right)+\left(1-\delta_{z}\right) \tilde{z}_{t-1}+\left(\hat{r}_{t}-\hat{r}_{t}^{*}\right)+\psi_{z t} \\
\hat{\imath}_{t}=\hat{r}_{t}+E_{t}\left(\hat{\pi}_{t+1}\right),
\end{gathered}
$$

\footnotetext{
${ }^{2}$ The appendix discusses the relation of this stylized model to the form used in BKL (2006). Note that we have changed the definition of the exchange rate so it is expressed as the number of units of foreign currency purchased by a unit of domestic currency (so that an increase denotes an appreciation).
} 


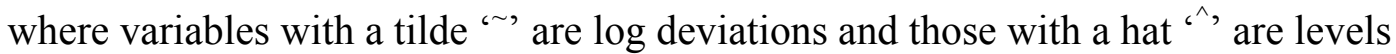
deviations from some equilibrium values, which may be non-stationary series. $\psi_{t}$ 's are terms added into the equations to reconcile models originally expressed in 'levels' with those expressed as 'gaps'. In this system $\tilde{y}_{t}$ is an output gap, $\hat{\imath}_{t}$ and $\hat{r}_{t}$ are deviations of the nominal and real interest rates from their equilibrium values, $\hat{\pi}_{t}$ is an inflation rate expressed as a deviation from whatever the inflation target is, and $\tilde{z}_{t}$ is the log deviation of the real exchange rate from equilibrium. An asterisk ${ }^{*}$, denotes foreign values of variables, and $\varepsilon_{t}$ are structural shocks. In BKL, oil price inflation enters into a number of equations and there is a difference between the underlying and headline inflation rates. Since oil prices are exogenous it is best to examine the simpler system. We will treat the time unit as being quarterly.

It is sometimes useful to re-write equations (1) and (2) as:

$$
\begin{gathered}
\Delta \tilde{y}_{t}=\beta_{\text {lead }} E_{t}\left(\Delta_{2} \tilde{y}_{t+1}\right)+\left(\beta_{\text {lag }}+\beta_{\text {lead }}-1\right) \tilde{y}_{t-1}-\beta_{r} \hat{r}_{t-1}-\beta \tilde{z}_{t-1}+\beta_{f} \tilde{y}_{t}^{*}+\psi_{y t}+\varepsilon_{t}^{y} \\
\Delta \tilde{\pi}_{t}=\alpha_{\text {lead }} E_{t}\left(\Delta_{2} \tilde{\pi}_{t+1}\right)+\alpha_{y} \tilde{y}_{t}-\alpha_{z} \Delta \tilde{z}_{t}+\psi_{\pi t}+\varepsilon_{t}^{\pi} .
\end{gathered}
$$

Expressing the equations in this form has two advantages. First, they may point to some possible difficulties with the specifications in a particular context. Second, they can be extremely useful when considering how adequate a representation of the data the model is likely to provide. In relation to the first point, consider the inflation equation. If $\tilde{y}_{t}$ is a very persistent process, then it is extremely difficult to reconcile this with the fact that the change in inflation and the exchange rate are likely to be close to white noise, with the implication that the shock $\varepsilon_{t}^{y}$ will need to be made highly persistent. Such an event probably calls into question the specification of the model, i.e. the "shock" is more properly interpreted as an "error term" and the appropriate response is to look at how the model might be adjusted. A similar (but converse) statement may be made about the output equation if $\beta_{\text {lag }}+\beta_{\text {lead }}=1$. Then weak serial correlation in output growth has to be made consistent with what is typically strong persistence in exchange rate change, real interest rates and the foreign output gap. The second advantage becomes important once one considers estimation and evaluation of the model, something we will discuss in a later paper.

\section{EXTENDING THE BKL MODEL}

We propose to modify BKL by appealing to some of the structure of DSGE models of an open economy set out in papers such as Justiniano and Preston (2005), Smets and Wouters (2003) and Nimark (2007). In these papers there are Euler equations which have the structure of (1) but which pertain to an absorption (expenditure) gap rather than an output gap. 
For example in DSGE models with habit persistence in consumption we would have an Euler equation of the form

$$
\tilde{c}_{t}=f_{\text {lead }} E_{t} \tilde{c}_{t+1}+f_{\text {lag }} \tilde{c}_{t-1}-f_{r} \hat{r}_{t-1}+\overparen{f_{\text {lag }} q_{t-1}-q_{t}+f_{\text {lead }} E_{t} q_{t+1}}+\varepsilon_{t}^{c}
$$

where $\tilde{c}_{t}$ is a $\log$ deviation from some permanent component $q_{t}\left(=\log Q_{t}\right)$, and the term $\psi_{c t}=\overparen{f_{\text {lag }} q_{t-1}-q_{t}+f_{\text {lead }} E_{t} q_{t+1}}$ is built into the relation because the Euler equation is fundamentally in terms of the levels of consumption and not naturally expressed in a gap form. Thus the fact that BKL works with variables that are deviations from some equilibrium components means that it is hard to interpret its equations as coming from a DSGE model (unless of course $f_{\text {lag }}+f_{\text {lead }}=1$ and $q_{t}$ is a pure random walk). If the Euler equations apply to levels then there are missing terms in the BKL equations that can cause biases if the parameters were estimated.

In addition to (6) there will also be investment (and government expenditure) equations with a similar structure. The former is determined by the rate of return on investment relative to the rate of interest - see Casares and McCallum (2006). To handle this one would need to develop an equation for the rate of return to investment and so the production side of the economy would need to be made explicit. This might be desirable but, for the moment, we will ignore that complication and instead think of there being a total absorption equation (as measured by Gross National Expenditure, $\left.n_{t}\right)$, which has the same form as (6) above, except that we ignore the issues relating to the presence of $q_{t}$ in the equation:

$$
\tilde{n}_{t}=h_{\text {lead }} E_{t} \tilde{n}_{t+1}+h_{\text {lag }} \tilde{n}_{t-1}-h_{r} \hat{r}_{t-1}+\varepsilon_{t}^{n}
$$

Now in DSGE models of an open economy there is an identity connecting total absorption (GNE), domestic output (GDP), exports (X) and imports (M). In level terms, this has the form $Y_{t}=N_{t}+X_{t}-M_{t}$, so that, defining expenditure, export and import gaps to be relative to the same permanent component $Q_{t}$ as used in forming the GDP gap, produces :

$$
\frac{Y_{t}}{Q_{t}}=\frac{N_{t}}{Q_{t}}+\frac{X_{t}}{Q_{t}}-\frac{M_{t}}{Q_{t}} .
$$

Log-linearization around equilibrium paths produces an identity of the form:

$$
\tilde{y}_{t}=\omega_{n} \tilde{n}_{t}+\omega_{x} \tilde{x}_{t}-\omega_{m} \tilde{m}_{t}+\varepsilon_{t}^{y}
$$


where the lower case variables with a tilde are expressed in $\log$ deviations from $Q_{t}$. The shock $\varepsilon_{t}^{y}$ would be zero if the linearized relation held exactly but it may capture preference shifts towards domestic goods in a simple fashion. In the simulations we report later it is set to zero.

Equations then need to be provided for import and export gaps. For imports (see (10) below), the structure of the models generally mean that the percentage of imports in total expenditure is a function of the relative price of imports to domestic goods, expressed in domestic currency, as well as some expenditure variable. We will assume that the relative price variable is proxied by the real exchange rate. Since we are modeling the import gap this will imply a dependence upon the real exchange rate gap $\tilde{z}_{t}$.

One problem with this formulation is that there may be raw material imports. Then an import aggregator in a DSGE model would have the ratio of imports to total output depending on relative prices. Total output is not likely to be observable but value added (GDP) is often taken to be its proxy, so that we might expect GDP to be a better measure of the demand for imports (at given relative prices). This suggests that we either form a weighted average of $n_{t}$ and $y_{t}$ with the weights set to sum to unity or utilize information about how much of imports is likely to be related to output rather than final expenditure.

In a similar way, the fraction of exports to foreign demand can be made to depend upon the price of exported goods to the price of foreign goods. Again it is a question of whether to relate this to foreign expenditure, but we will just use foreign GDP since BKL had that as representing the foreign sector influence. The relative price variable will be taken to be the exchange rate gap $\tilde{z}_{t}$.

Putting the above arguments together produces equilibrium values (denoted by a bar ‘-, ):

$$
\begin{aligned}
& \bar{x}_{t}=k_{x} \tilde{y}_{t}^{*}-\lambda_{x} \tilde{z}_{t} \\
& \bar{m}_{t}=k_{m} \tilde{y}_{t}+\lambda_{m} \tilde{z}_{t}
\end{aligned}
$$

where we have allowed the income and price elasticities to be other than unity. We will probably want to allow for some adjustment scheme as it is unlikely that the adjustment to a price change or expenditure change would be immediate and equivalent dynamics have been incorporated into the other equations of the model. We will borrow the idea in Hostland and $\operatorname{Karam}(2005,2006)$ of allowing these to adjust via an error correction mechanism to equilibrium values. Hence,

$$
\Delta \tilde{x}_{t}=a\left(\bar{x}_{t}-\tilde{x}_{t-1}\right)+\varepsilon_{t}^{x}
$$




$$
\Delta \tilde{m}_{t}=b\left(\bar{m}_{t}-\tilde{m}_{t-1}\right)+\varepsilon_{t}^{m}
$$

Finally, to emulate the orientation of DSGE models of an open economy we propose that (1) be replaced by (7), (8), (9) and (10).

This seems to be the simplest possible extension of BKL that preserves the ideas of DSGE models of open economies but results in minimal changes to the existing model. It should be noted that EBKL will not specialize to BKL. To see why, suppose one substituted the identity (8) into (7) giving an equation in $\tilde{y}_{t}$. This equation would have forward and lagged values of the real exchange rate in it as well as the other elements that are in (1).

Now the model above (and BKL) focuses only upon flows. Stocks of real and financial assets are ignored. In the case of an open economy this doesn't seem satisfactory as rising stocks of external debt can be expected to lead to pressures upon the economy to engage in policies that stabilize this debt. To this end we want to derive an expression for the accumulation of any external debt. Let $S_{t}$ be the nominal exchange rate (amount of foreign currency for one unit of domestic currency), so that $P_{x t} / S_{t}$ and $P_{m t} / S_{t}$ are the prices of exports and imports in domestic currency ( $P_{x t}$ and $P_{m t}$ being export and import prices set on world markets), and let $D_{t}$ be the level of foreign debt measured in domestic currency. Then net external debt evolves as

$$
D_{t}=\left(1+i_{t}\right) D_{t-1}^{d}+\left(1+i_{t}^{*}+r p_{t}\right) D_{t-1}^{f} / S_{t}+\left(P_{m t} / S_{t}\right) M_{t}-\left(P_{x t} / S_{t}\right) X_{t}
$$

where $D_{t}^{d}$ is the amount of debt that is issued in domestic currency, $D_{t}^{f}$ is the amount in foreign dollars, $i_{t}^{*}$ is the foreign interest rate, and $r p_{t}$ is a risk premium that has to be paid to external debt holders over the foreign interest rate. The existence of two interest rates means that foreign and domestic debt are not perfectly substitutable. Then we would have

$$
D_{t}=\left[k_{d}\left(1+i_{t}\right)+k_{f}\left(1+i_{t}^{*}+r p_{t}\right)\left(S_{t-1} / S_{t}\right)\right] D_{t-1}+\left(P_{m t} / S_{t}\right) M_{t}-\left(P_{x t} / S_{t}\right) X_{t}
$$

where $k_{d}=\frac{D_{t-1}^{d}}{D_{t-1}}$ and $k_{f}=\frac{D_{t-1}^{f} / S_{t-1}}{D_{t-1}}$ are the shares of (external) debt that are issued and denominated in domestic and foreign currency. This allows for valuation effects on debt stocks. We assume that $k_{d}$ and $k_{f}$ are constant over time, although if the exchange rate changes are large enough this won't be true. For emerging countries it is likely that $k_{f}=1$ (all external debt is denominated in foreign currency). 
Measuring the stock of debt relative to the nominal value of the permanent component $\left(Q_{t}\right)$ of GDP, and taking its price index to be the aggregate price level, we obtain an equation for the debt-to-GDP ratio equation as follows:

$$
d_{t}=\frac{D_{t}}{P_{t} Q_{t}}=\left[k_{d}\left(1+i_{t}\right)+k_{f}\left(1+i_{t}^{*}+r p_{t}\right)\left(S_{t-1} / S_{t}\right)\right]\left(\frac{D_{t-1}}{P_{t} Q_{t}}\right)+\frac{P_{m t}}{S_{t} P_{t}} \frac{M_{t}}{Q_{t}}-\frac{P_{x t}}{S_{t} P_{t}} \frac{X_{t}}{Q_{t}}
$$

We need to simplify the term in square brackets above. The more complex component is

$$
\left[k_{f}\left(1+i_{t}^{*}+r p_{t}\right)\left(S_{t-1} / S_{t}\right)\right]\left(\frac{D_{t-1}}{P_{t} Q_{t}}\right)=k_{f}\left(1+i_{t}^{f}\right)\left(S_{t-1} / S_{t}\right)\left(\frac{D_{t-1}}{P_{t} Q_{t}}\right)
$$

where $1+i_{t}^{f}=1+i_{t}^{*}+r p_{t}$, which we consider next. It is ${ }^{3}$

$$
\begin{aligned}
& k_{f}\left(1+i_{t}^{f}\right)\left(1-\Delta s_{t}\right) d_{t-1} \frac{P_{t-1} Q_{t-1}}{P_{t} Q_{t}} \\
& =k_{f} d_{t-1}\left(1+i_{t}^{f}\right)\left(1-\Delta s_{t}\right)\left(1-\Delta p_{t}-\Delta q_{t}\right) \\
& =k_{f} d_{t-1}\left(1+i_{t}^{f}\right)\left(1-\Delta s_{t}\right)\left(1-\psi_{t}\right)
\end{aligned}
$$

Now linearizing $\left(1+i_{t}^{f}\right)\left(1-\Delta s_{t}\right)\left(1-\psi_{t}\right)$ around $\bar{i}^{f}, \Delta s_{t}=0$ and $\bar{\psi}$ we get

$$
\left(1+\bar{i}^{f}\right)(1-\bar{\psi})+\overparen{(1-\bar{\psi}) \hat{i}_{t}^{f}-\left(1+\bar{i}^{f}\right)(1-\bar{\psi}) \Delta s_{t}-\left(1+\bar{i}^{f}\right) \hat{\psi}_{t}}=\left(1+\bar{i}^{f}\right)(1-\bar{\psi})+\overparen{\phi}_{2 t}
$$

Hence

$$
\begin{aligned}
k_{f}\left(1+i_{t}^{f}\right)\left(S_{t-1} / S_{t}\right)\left(\frac{D_{t-1}}{P_{t} Q_{t}}\right) & \simeq k_{f} d_{t-1}\left[\left(1+\bar{i}^{f}\right)(1-\bar{\psi})+\phi_{2 t}\right] \\
& =k_{f}\left(\bar{d}+\hat{d}_{t-1}\right)\left[\left(1+\bar{i}^{f}\right)(1-\bar{\psi})+\phi_{2 t}\right] \\
& \simeq k_{f} \bar{d}\left(1+\bar{i}^{f}\right)(1-\bar{\psi})+k_{f} \bar{d} \phi_{2 t}+k_{f} \hat{d}_{t-1}\left(1+\bar{i}^{f}\right)(1-\bar{\psi})
\end{aligned}
$$

\footnotetext{
${ }^{3} s_{t}, p_{t}$ and $q_{t}$ are the logs of the nominal exchange rate, the price level, and the permanent
} GDP component, respectively. 
where $\hat{d}_{t}=d_{t}-\bar{d}$ and we have ignored terms of lower order such as $\hat{d}_{t-1} \phi_{2 t}$. A similar expansion holds for the term $k_{d}\left(1+i_{t}\right)\left(\frac{D_{t-1}}{P_{t} Q_{t}}\right)$ so that

$$
k_{d}\left(1+i_{t}\right)\left(\frac{D_{t-1}}{P_{t} Q_{t}}\right) \simeq k_{d} \bar{d}(1+\bar{i})(1-\bar{\psi})+k_{d} \bar{d} \phi_{1 t}+k_{d} \hat{d}_{t-1}(1+\bar{i})(1-\bar{\psi})
$$

where $\phi_{1 t}=(1-\bar{\psi}) \hat{\imath}_{t}-(1+\bar{i}) \hat{\psi}_{t}$. Substituting these terms into (13), but ignoring the current account terms for the moment, gives

$$
d_{t}=\bar{d} \alpha+\alpha \hat{d}_{t-1}+k_{f} \bar{d} \phi_{2 t}+k_{d} \bar{d} \phi_{1 t}
$$

where $\alpha=(1-\bar{\psi})\left[k_{f}\left(1+\bar{i}^{f}\right)+k_{d}(1+\bar{i})\right]$. Now we need the equilibrium condition that $\alpha=1$, i.e. the effective nominal equilibrium interest rate on foreign debt equals the rate of growth of potential output plus the inflation rate. Otherwise there will be no possibility of a steady state for the debt to income ratio. In this case,

$$
\hat{d}_{t}=d_{t}-\bar{d}=\hat{d}_{t-1}+k_{f} \bar{d} \phi_{2 t}+k_{d} \bar{d} \phi_{1 t}
$$

Including the current account terms, we now define $Z_{t}$ as $\left(\frac{P_{t} S_{t}}{P_{m t}}\right)$, as a ratio of CPI's (following BKL), giving an expression for the current balance term of $Z_{t}^{-1}\left(\frac{M_{t}}{Q_{t}}\right)-Z_{t}^{-1} T O T_{t}\left(\frac{X}{Q_{t}}\right)$, where $T O T_{t}$ denotes the terms of trade. Consequently, the debt equation becomes

$$
\Delta \hat{d}_{t}=k_{f} \bar{d} \phi_{2 t}+k_{d} \bar{d} \phi_{1 t}+\omega_{m}\left(-\tilde{z}_{t}+\tilde{m}_{t}-\tilde{y}_{t}\right)-\omega_{x}\left(-\tilde{z}_{t}+\tilde{x}_{t}-\tilde{y}_{t}+\widetilde{\text { tot }_{t}}\right)
$$

where tot $_{t}$ is the $\log$ of the terms of trade $\left(\frac{P_{x t}}{P_{m t}}\right){ }^{4}$ In DSGE models there is generally some cost effectively added to the evolution of debt equation in order to ensure that the interest rate paid on foreign debt rises with the level of debt. Unless this is done there is no steady state for the debt/income ratio. There are a number of ways of doing this which are discussed in

\footnotetext{
${ }^{4}$ In doing this we have replaced Q with $\mathrm{Y}$ since we are measuring the debt ratio, imports and exports to GDP rather than potential GDP.
} 
Schmitt-Grohe and Uribe (2003). One of the ways is to incorporate a risk premium that rises with the level of external debt into the UIP equation and that was essentially the strategy used in Hostland and Karam (2006). We adopt this approach here so that the real exchange rate evolves as

$$
\tilde{z}_{t}=\delta_{z} E_{t} \tilde{z}_{t+1}+\left(1-\delta_{z}\right) \tilde{z}_{t-1}+\left(\hat{r}_{t}-\hat{r}_{t}^{*}-\theta \hat{d}_{t-1}\right)+\varepsilon_{t}^{z}
$$

Obviously there are some strong assumptions in the derivation above. A lot of cross product terms have been dropped and, if the change in the nominal exchange rate is very large, the linearization may be inaccurate. In that case one may need to use second order approximations. The restriction that $\alpha=1$ may also be problematic over any finite time horizon and one may need to think about how it is to be handled in any context in which one is exploring policy options.

The advantage of this re-formulation of BKL would seem to be that it corresponds to the experience of many small open economies. A surge of demand in these economies can cause a rise in expenditure but, if domestic production does not meet the demand, the effect on prices is more muted than in a closed economy, since the demand dissipates into imports. Of course this then creates a depreciation in the exchange rate, and that will cause some inflation, but the lagged adjustments can be very different to open economy models, particularly if pass-through is very slow. ${ }^{5}$ The presence of exports, imports and the terms of trade in the model also presents the opportunity of allowing for some extra dimensions in discussing policy issues.

\section{An ILlustration OF THE EBKL MODEL}

\section{A. Calibrating EBKL to the Canadian Economy}

There are clearly issues arising in relation to the calibration of EBKL. There are a number of new parameters (even if we assume that the parameters in (7) might be taken to be the same as (1)) in the form of the trade elasticities $\left(\lambda_{x}, \lambda_{m}, \kappa_{x}, \kappa_{m}\right)$, the ECM adjustment rates $a, b$ and the risk premium effect captured by $\theta$. There is probably evidence on the first two sets of parameters for most countries, but there has been less work on the last $(\theta)$, although sometimes there may be some opinions of the likely magnitude.

BKL looked at Canadian policy issues with parameters chosen from Canadian data. We do the same here. We work with quarterly data from 1980-2004 in order to calibrate the

\footnotetext{
${ }^{5}$ This difference can be pronounced for a set of countries subject to a more rapid pass-through of imported goods prices into domestic consumption prices.
} 
parameters of EBKL. In all cases equilibrium values for GDP, the real exchange rate, real interest rates and other variables were taken from the BKL data base. The GNE gap was constructed relative to the potential (equilibrium) level of GDP. Figure 1 shows the difference between the (Canadian) GDP and GNE gaps.

Figure 1. Plot of GNE and GDP Gaps in Canada (1970Q1-2005Q4)

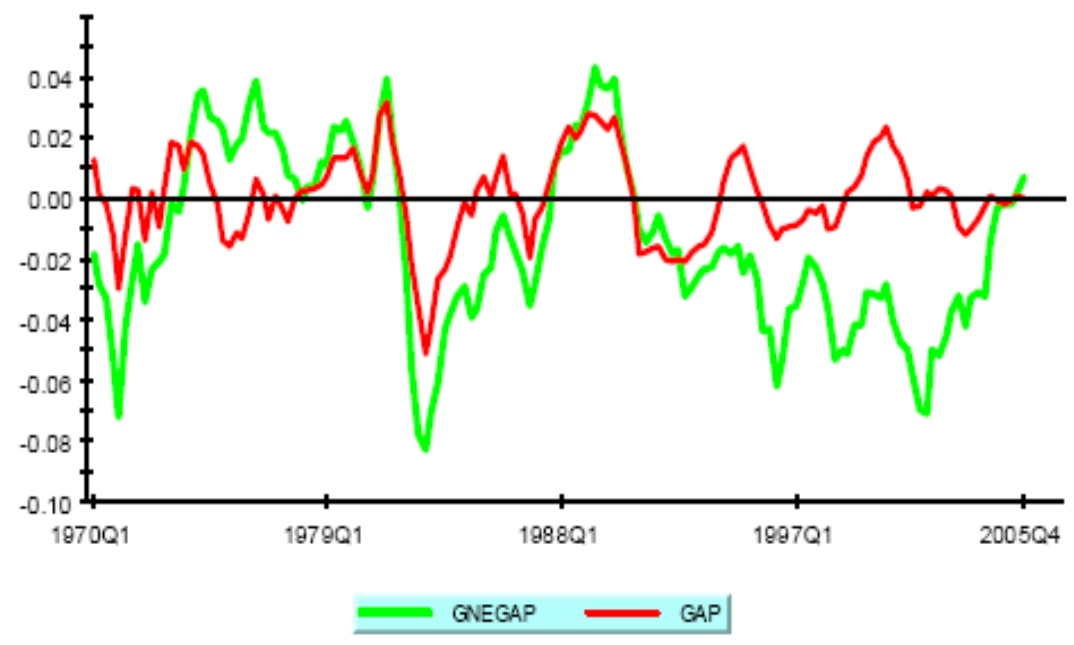

It is clear that in recent years there has been a substitution away from expenditure towards savings and that has resulted in a balance of trade surplus.

The import and output gaps are more complex to determine. Figures 2 and 3 compare the rate of growth of imports and exports to the long-run (1970-2005) growth rate in GDP, from which it is apparent that computing gaps based upon GDP growth would be misleading. We therefore used a deterministic trend in the own series to form each of these gaps. To some extent the growth may be simply a reflection of the formation of NAFTA and the earlier FTA, as it seems as if the higher growth started around 1989 and then accelerated after 1994. Since we are dealing with aggregate imports and exports there is no issue about whether NAFTA was simply trade diversion. There has been a substantial boost to trade in the aggregate.

We use data over 1980-2005 in order to determine some suitable values for the trade elasticities and adjustment terms. Fitting (12) to import gap data (using the GNE gap as the expenditure variable) we find that $b=.23 ; \lambda_{m}=.8$ and $k_{m}=1.1$. The same regression with exports gives $\mathrm{a}=.17, k_{x}=3$ and $\lambda_{x}=-.6$. However we could set $\lambda_{x}=-1$ without difficulty and this was done. The problem with the magnitude of the US gap coefficient $\left(k_{x}\right)$ can be seen in Figure 4. Both strong recessions and expansions produce a large increase in this coefficient. Therefore we will put $k_{x}=1.5$. The parameters $h_{\text {lead }}, h_{\text {lag }}$ and $h_{r}$ were taken to be the corresponding values for $\beta_{\text {lead }}, \beta_{\text {lag }}$ and $\beta_{r}$ in BKL's output gap equation, and the Phillips curve and interest rate rule parameters were those of BKL. In all cases however we 
need to adjust the values to reflect the fact that BKL measure interest rates and inflation as annualized whereas our model utilizes quarterly measures.

Figure 2. Average Growth Rate of Imports Less Long-Run Growth in GDP (and 95\% Error Bands), Rolling Regression

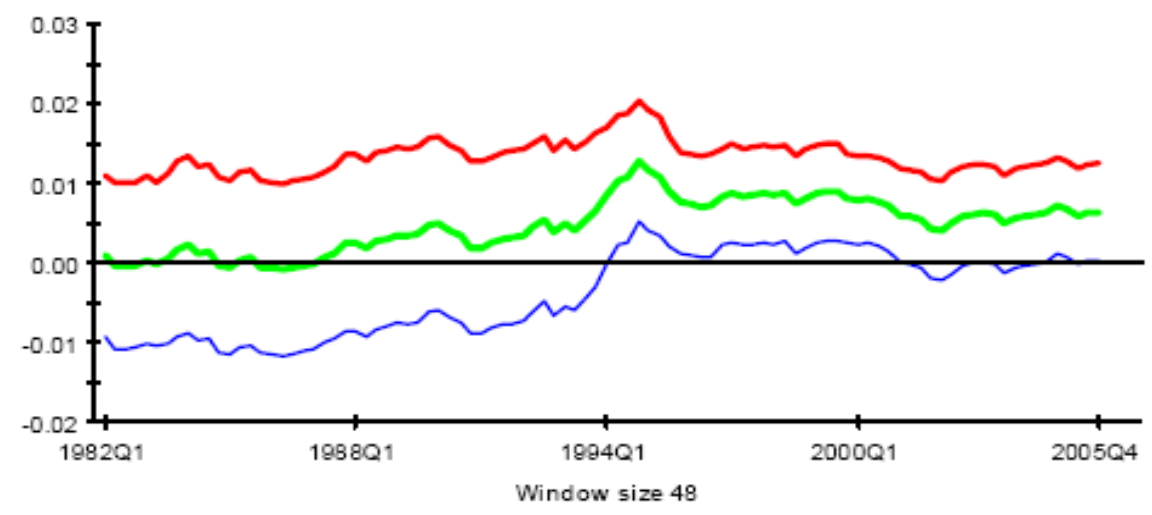

Figure 3. Average Growth Rate of Exports Less Long-Term Average Growth Rate in GDP (and 95\% Bands); Rolling Regression

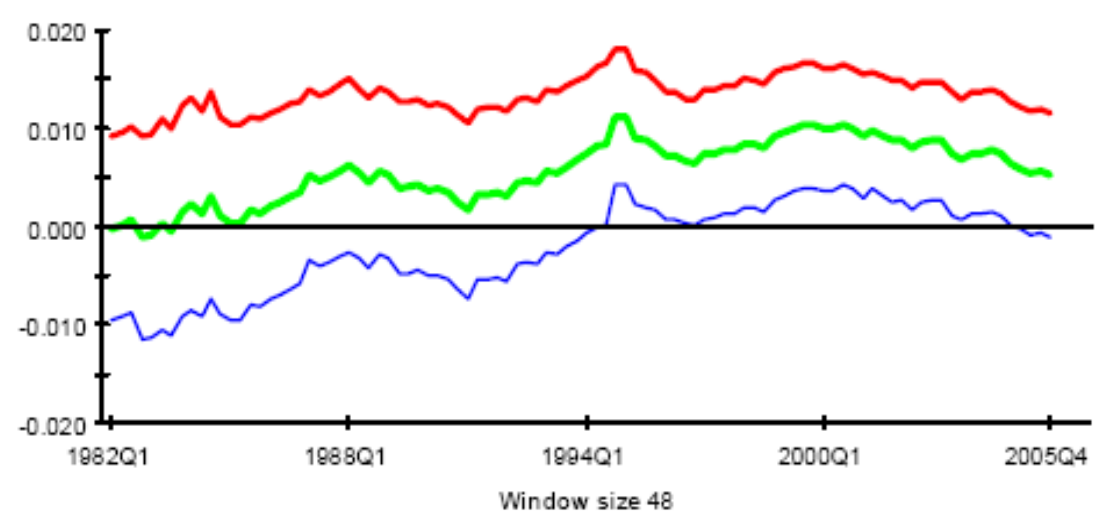


Figure 4. Plot of Export Regression Predictions Against US Output Gap Along with $1.5^{*}$ USGAP

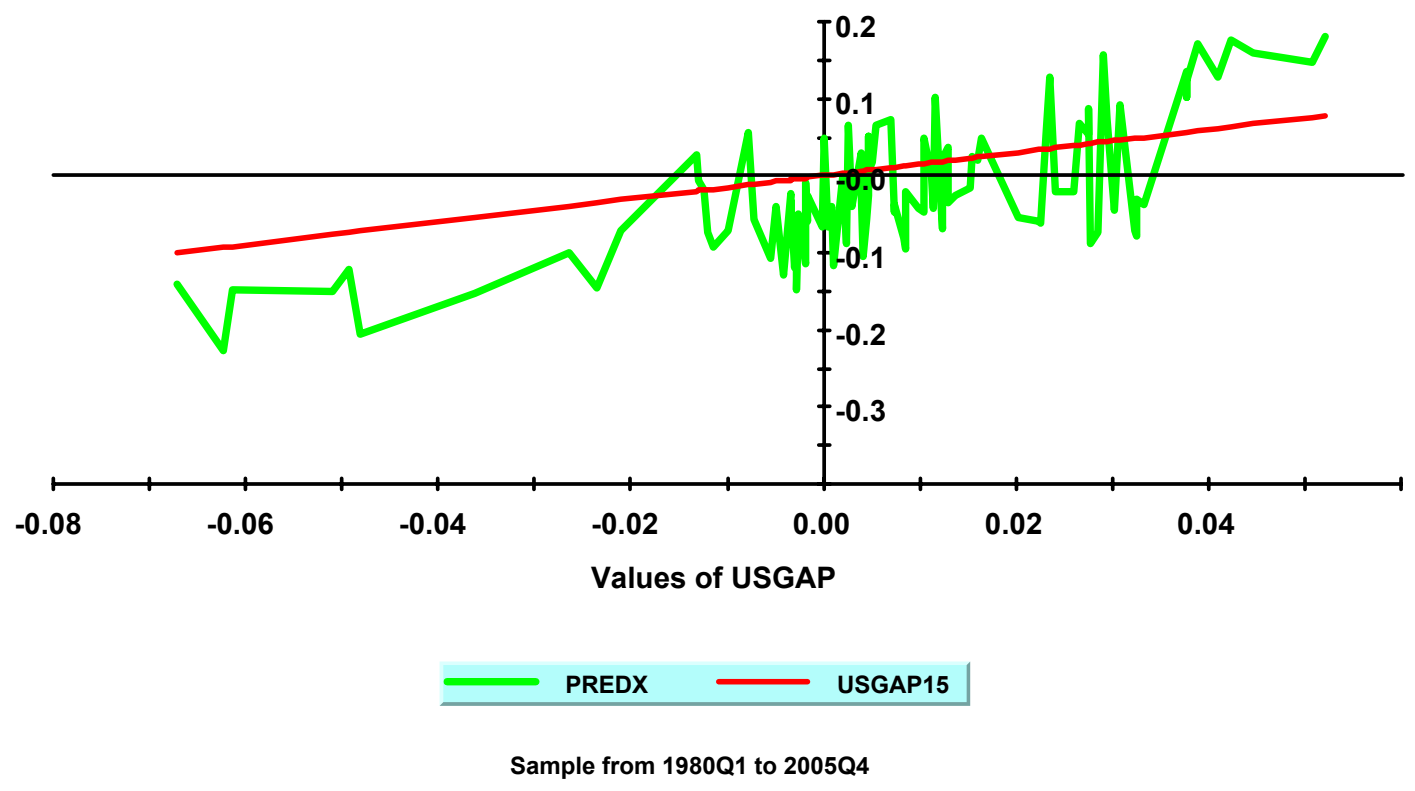

Once all parameters are assigned to the model, the shocks can be computed and their standard deviations estimated. The shocks were all treated as being serially uncorrelated. The external variables $\tilde{y}_{t}^{*}, \widetilde{o t}_{t}, \hat{l}_{t}^{*}, \pi_{t}^{*}$ were all treated as AR(1) processes and parameters estimated using the 1980-2005 data. Tables 1 and 2 give a complete listing of the parameters used. 
Table 1. Structural Parameter Estimates for Canada

\begin{tabular}{|c|c|c|c|c|}
\hline$h_{\text {lead }}$ & .1 & & $\delta_{z}$ & 1 \\
\hline$h_{\text {lag }}$ & .85 & & $\theta$ & 0.04 \\
\hline$h_{r}$ & .4 & & $\lambda_{x}$ & -1.0 \\
\hline$\alpha_{\text {ld }}$ & .2 & & $\kappa_{x}$ & 1.5 \\
\hline$\alpha_{y}$ & .075 & & $\lambda_{m}$ & 0.8 \\
\hline$\alpha_{z}$ & .025 & & $\kappa_{m}$ & 1.1 \\
\hline$\gamma_{\text {lag }}$ & .5 & & $k_{f}$ & 1 \\
\hline$\gamma_{\pi}$ & 2 & & $a$ & .17 \\
\hline$\gamma_{y}$ & .125 & & $b$ & .23 \\
\hline
\end{tabular}

Table 2. Parameter Values for Shocks

\begin{tabular}{|c|c|c|c|c|c|c|}
\hline$\sigma_{n}$ & .0087 & $\sigma_{y^{*}}$ & .007 & $\rho_{y^{*}}$ & .8 & \\
\hline$\sigma_{y}$ & 0 & $\sigma_{\pi^{*}}$ & .004 & $\rho_{\pi^{*}}$ & .642 & \\
\hline$\sigma_{\pi}$ & .0045 & $\sigma_{i^{*}}$ & .002 & $\rho_{i^{*}}$ & .95 & \\
\hline$\sigma_{i}$ & .0108 & $\sigma_{x}$ & .026 & $\rho_{x}$ & 0 & \\
\hline$\sigma_{z}$ & .0139 & $\sigma_{m}$ & .029 & $\rho_{m}$ & 0 & \\
\hline & \multicolumn{7}{|c|}{$\sigma_{t t}$} & .031 & $\rho_{t t}$ & .91 & \\
\hline
\end{tabular}

One difference to BKL is that we impose $\delta_{z}=1$ in the UIP equation, the reason being that one obtained a better match to the outcomes for the Canadian economy with this choice rather than the $\delta_{z}=.5$ used by BKL. Table 3 shows this.

Table 3. Variances of Data and Model Variables

\begin{tabular}{|c|c|c|c|}
\hline & Data & $\begin{array}{c}\text { Model } \\
\delta_{z}=.5\end{array}$ & $\begin{array}{c}\text { Model } \\
\delta_{z}=1\end{array}$ \\
\hline$\sigma_{n}$ & .029 & .059 & .043 \\
\hline$\sigma_{y}$ & .014 & .028 & .025 \\
\hline$\sigma_{\pi}$ & .009 & .008 & .008 \\
\hline$\sigma_{z}$ & .049 & .164 & .078 \\
\hline$\sigma_{i}$ & .009 & .022 & .022 \\
\hline
\end{tabular}


It is apparent from this table that the model tends to produce too much volatility in variables. To some extent this may be due to the high volatilities of some of the shocks e.g. imports and exports, and one would need to examine this calibration more carefully before use.

\section{B. Experiments with the Calibrated EBKL Model}

Below we provide some impulse responses. Figure 5 shows the effect of an interest rate shock upon GNE and GDP. One can see obvious differences in the responses. The rise in the interest rate would appreciate the exchange rate and the price effect would tend to increase imports and decrease exports. There is also an income effect upon imports and it seems as if the decline in GNE coming from the real interest rate rise has a bigger effect upon the quantity of imports than the exchange rate effect so that after about a year GNE has fallen by more than GDP does. Figure 6 shows the effects of an interest rate increase upon inflation under the two cases where $\theta=0$, and when $\theta=.02$ (risk premium). In the first scenario the debt levels increase permanently and in the second it converges back to its equilibrium position and the inflation responses in the medium term tend to be better (stronger) when there is an impact of mounting external debt.

Figure 5. Effects of Interest Rate Shock on GNE and GDP gaps

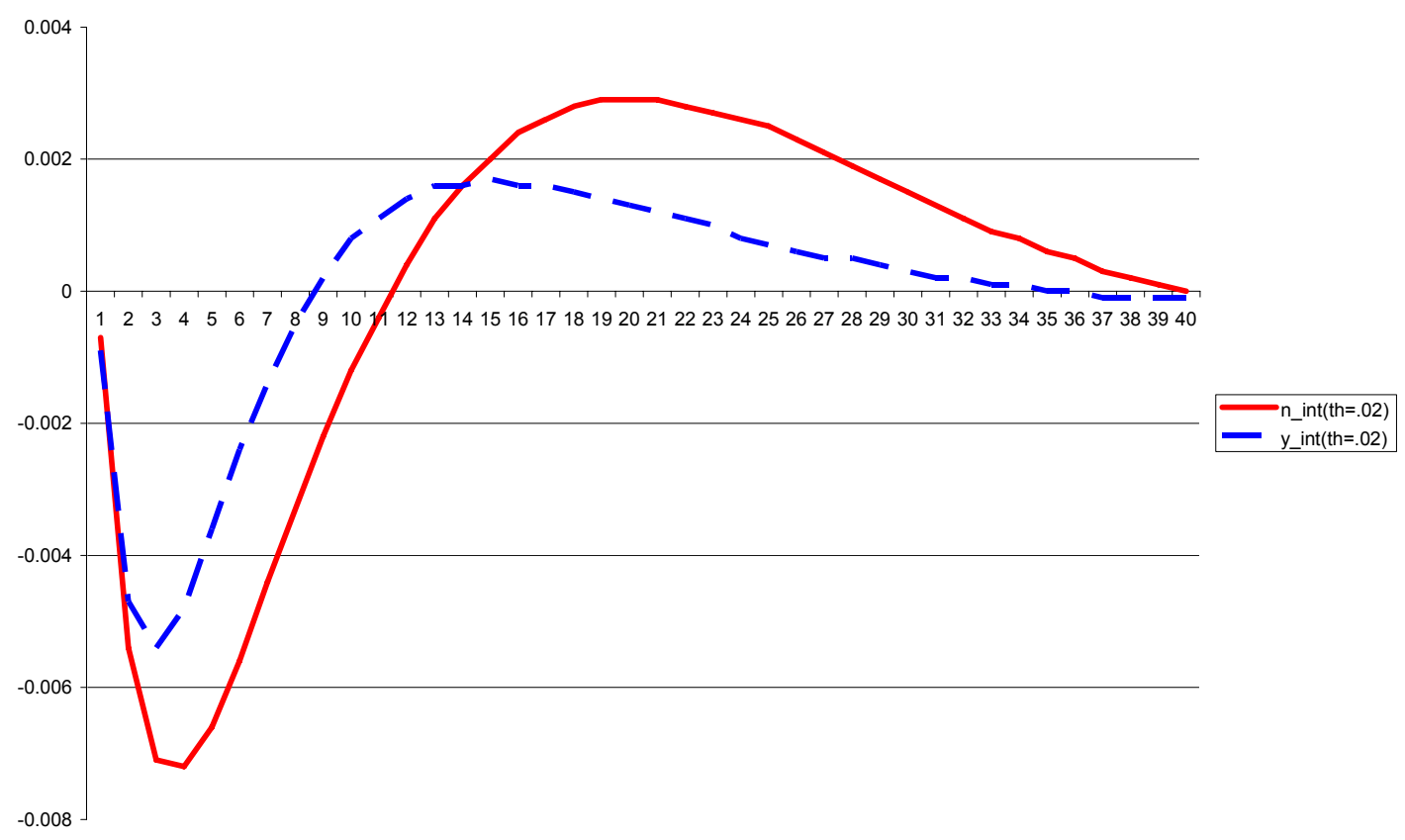


Figure 6. Effects of Interest Rate Shock on Inflation

With $(\theta=0.02)$ and Without $(\theta=0)$ Risk Premium

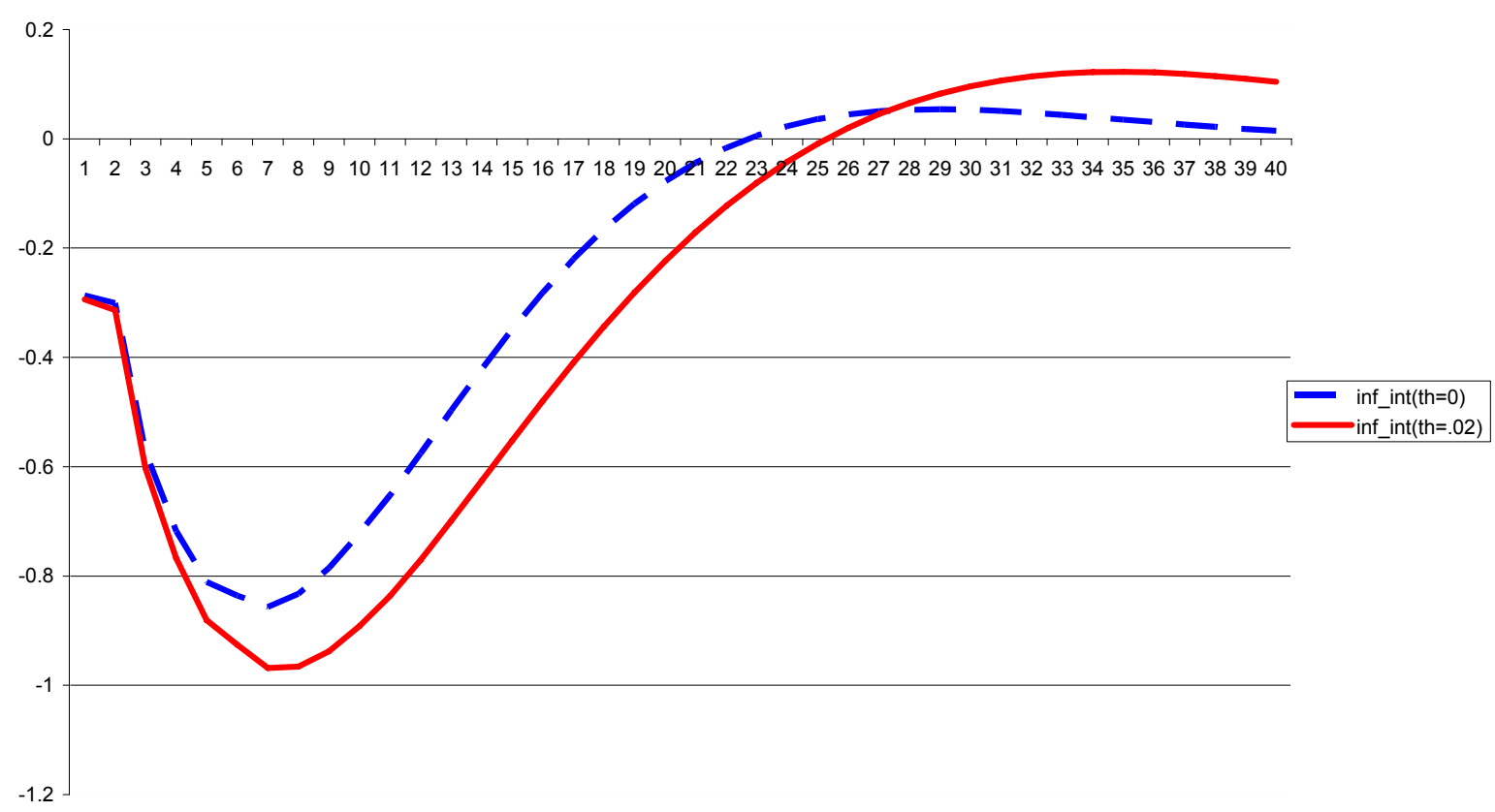

Figure 7. Effects of Terms of Trade Shock on GDP Gap

Debt Fully Denominated in Domestic $\left(k_{d}=1\right)$ or Foreign $\left(k_{f}=1\right)$ Currency

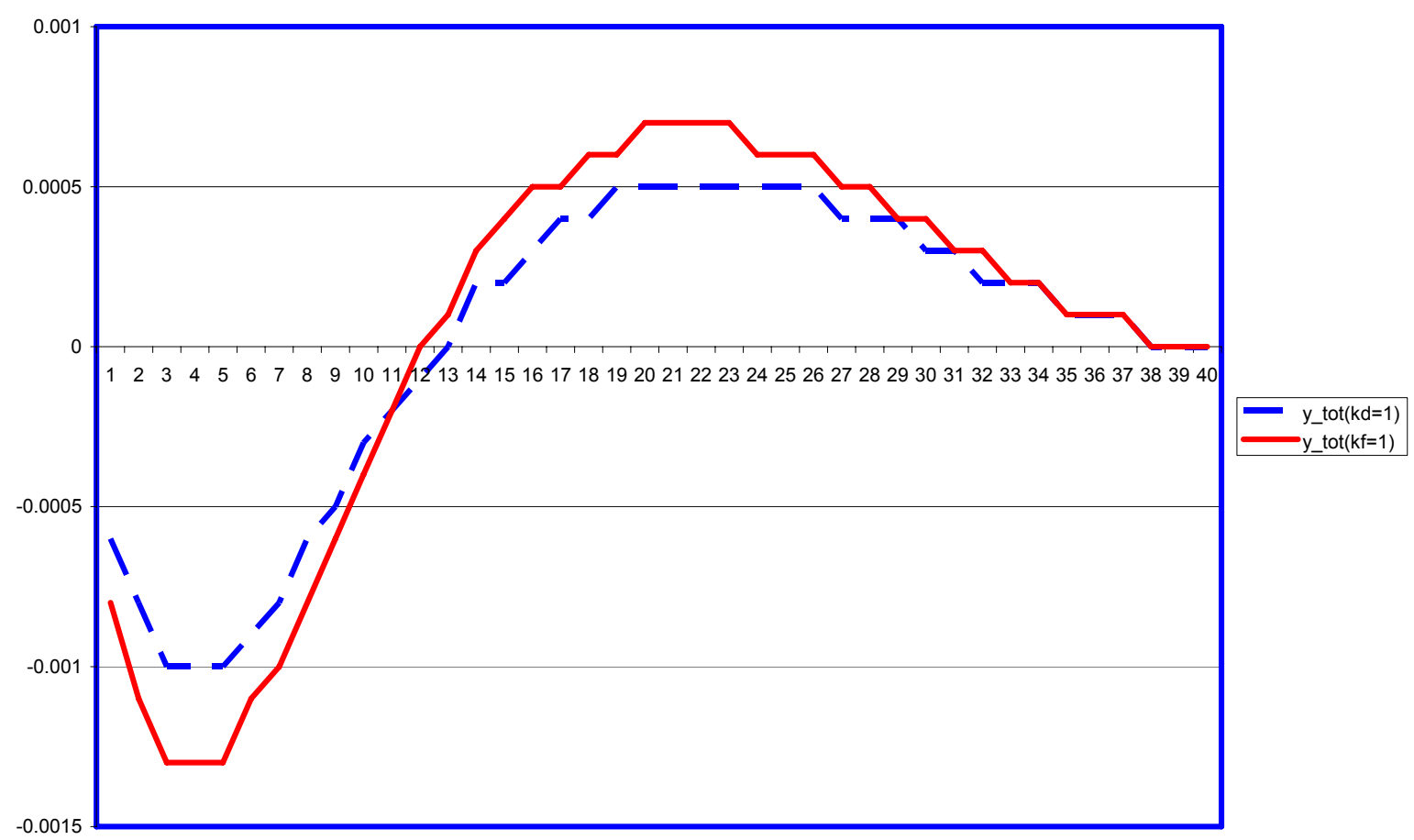


Figure 7 shows the impact of a terms of trade shock upon GDP. The rise in the terms of trade causes an exchange rate appreciation and so imports grow and exports decline, resulting in a contraction in GDP for some period. There are two simulations depending upon whether (external) debt is denominated in domestic $\left(k_{d}=1\right)$ or foreign $\left(k_{f}=1\right)$ currency. There is a stronger impact in the case of foreign currency financed (external) debt. The debt level responses are in Figure 8. When debt is foreign currency denominated, an appreciation will increase imports and reduce exports due to a price effect on these but an appreciation will tend to cause a reduction in debt measured in domestic currency when debt is foreign currency denominated. It is clear that we need to spend more time on this, but the model clearly provides very interesting dynamics and enables one to think about the consequences of things like terms of trade shocks.

Figure 8. Effects of Terms of Trade Shock on Debt-to-GDP Ratio Debt Fully Denominated in Domestic or Foreign Currency

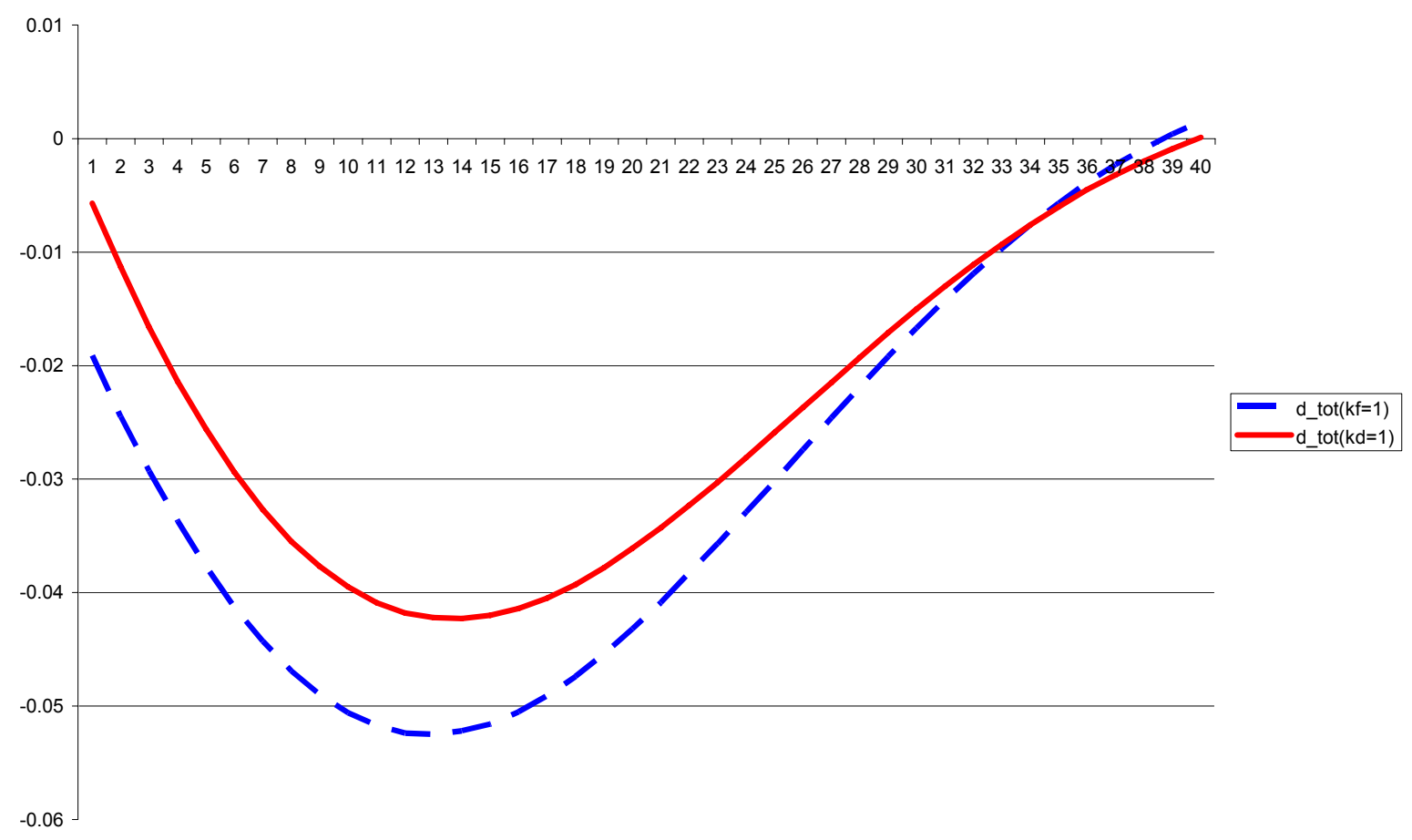




\section{Conclusion}

We have presented a simple extension of a model set out in Berg et al (2005) which allows for a distinction between absorption and output as occurs in open economies. The extension allows one to determine the accumulation of debt flows and so introduces some financial stocks into the model. Augmenting the model presented in Berg et al seems likely to be of use when dealing with emerging economies in which trade and financial flows are likely to be important for an analysis of policy options and for forecasting inflation and output growth. 


\section{APPENDIX: EBKL VERSUS THE STYLIZED EQUATIONS}

The actual BKL model ( and the one used in the empirical application), ignoring oil price terms and the distinction between headline and underlying inflation which this induces, has the form

$$
\begin{gathered}
\tilde{y}_{t}=\beta_{\text {lead }} E_{t}\left(\tilde{y}_{t+1}\right)+\beta_{\text {lag }} \tilde{y}_{t-1}-\beta_{r} \hat{r}_{t-1}-\beta_{z} z_{t-1}+\beta_{f} \tilde{y}_{t}^{*}+\varepsilon_{t}^{y} \\
\pi_{t}=\alpha_{\text {lead }} E_{t}\left(\pi 4_{t+4}\right)+\left(1-\alpha_{\text {lead }}\right) \pi 4_{t-1}+\alpha_{y} \tilde{y}_{t}-\alpha_{z} \Delta z_{t}+\varepsilon_{t}^{\pi} \\
i_{t}=\gamma_{\text {lag }} i_{t-1}+\left(1-\gamma_{\text {lag }}\right)\left(\bar{r}_{t}+\pi 4_{t}+\gamma_{\pi}\left(E_{t} \pi 4_{t+4}-\overline{\pi 4}_{t+4}\right)+\gamma_{y} \tilde{y}_{t}\right)+\varepsilon_{t}^{i} \\
z_{t}=\delta_{z} E_{t}\left(z_{t+1}\right)+\left(1-\delta_{z}\right) z_{t-1}+\left[\left(r_{t}-r_{t}^{*}-\bar{\rho}_{t}\right)\right]+\varepsilon_{t}^{z} \\
i_{t}=r_{t}+E_{t}\left(\pi_{t+1}\right) \\
\bar{\rho}_{t}=-\left(\bar{z}_{t}-\bar{z}_{t+1}\right)+\bar{r}_{t}-\bar{r}_{t}^{*} \\
\pi 4_{t}=\left[\pi_{t}+\pi_{t-1}+\pi_{t-2}+\pi_{t-3}\right] / 4
\end{gathered}
$$

where $i_{t}$ is the quarterly nominal interest rate, $\pi 4_{t+4}$ is the quarterly change in the annual inflation rate from period $t, z_{t}$ is the quarterly real exchange rate and $\pi_{t}$ is the quarterly inflation rate ${ }^{6}$. The model is partially in gap form but to convert it fully to that form we need to adjust the inflation equation, the interest rate rule and the exchange rate equation. First, we distinguish steady state (or permanent components) by a bar ${ }^{\text {'- }}$. These may vary over time. Then the BKL definition of the steady state nominal interest rate is related to the real rate and the annual inflation rate in the following way:

$$
\overline{i_{t}}=\bar{r}_{t}+E_{t} \bar{\pi}_{t+1}
$$

Then the interest rate equation can be written as

$$
i_{t}-\bar{i}_{t}=\gamma_{\text {lag }}\left(i_{t-1}-\bar{i}_{t-1}\right)+\left(1-\gamma_{\text {lag }}\right)\left[-\bar{i}_{t}+\bar{r}_{t}+\pi 4_{t}+\gamma_{\pi}\left(E_{t} \pi 4_{t+4}-\overline{\pi 4}_{t+4}\right)+\gamma_{y} \tilde{y}_{t}\right]-\gamma_{\text {lag }} \Delta \bar{i}_{t}+\varepsilon_{t}^{i}
$$

${ }^{6}$ In BKL $i_{t}$ and $\pi_{t}$ were annualized quantities and $\pi 4_{t}$ was the annual inflation rate 
Using $\hat{\imath}_{t}=i_{t}-\overline{i_{t}}$ produces

$$
\begin{aligned}
& \hat{\imath}_{t}=\gamma_{\text {lag }} \hat{\imath}_{t-1}+\left(1-\gamma_{\text {lag }}\right)\left[\widehat{\pi 4}_{t}+\gamma_{\pi} E_{t} \widehat{\pi 4}_{t+4}+\gamma_{y} \tilde{y}_{t}\right]+\psi_{i t}+\varepsilon_{t}^{i} \\
& \psi_{i t}=\left(1-\gamma_{\text {lag }}\right)\left(\overline{\pi 4}_{t}-E_{t} \bar{\pi}_{t+1}\right)-\gamma_{\text {lag }} \Delta \bar{i}_{t}
\end{aligned}
$$

The Phillips curve is

$$
\begin{aligned}
\pi_{t}-\bar{\pi}_{t} & =\alpha_{\text {lead }} E_{t}\left(\pi 4_{t+4}-\overline{\pi 4}_{t+4}\right)+\left(1-\alpha_{\text {lead }}\right)\left(\pi 4_{t-1}-\overline{\pi 4}_{t-1}\right) \\
& +\alpha_{y} \tilde{y}_{t}-\alpha_{z} \Delta\left(z_{t}-\bar{z}_{t}\right)+\psi_{\pi t}+\varepsilon_{t}^{\pi}
\end{aligned}
$$

where

$$
\psi_{\pi t}=\alpha_{\text {lead }} E_{t} \bar{\pi}_{t+4}-\bar{\pi}_{t}+\left(1-\alpha_{\text {lead }}\right) \bar{\pi}_{t-1}-\alpha_{z} \Delta \bar{z}_{t}
$$

This becomes

$$
\hat{\pi}_{t}=\alpha_{\text {lead }} \widehat{\pi 4}_{t+4}+\left(1-\alpha_{\text {lead }}\right) \widehat{\pi 4}_{t-1}+\alpha_{y} \tilde{y}_{t}-\alpha_{z} \Delta \tilde{z}_{t}+\psi_{\pi t}+\varepsilon_{t}^{\pi}
$$

Finally, the exchange rate equation is

$$
\begin{aligned}
z_{t}-\bar{z}_{t} & =\delta_{z} E_{t}\left(z_{t+1}-\bar{z}_{t+1}\right)+\left(1-\delta_{z}\right)\left(z_{t-1}-\bar{z}_{t-1}\right) \\
& +\left(1-\delta_{z}\right)\left(\bar{z}_{t-1}-\bar{z}_{t+1}\right)+r_{t}-\bar{r}_{t}-r_{t}^{*}+\bar{r}_{t}^{*}+\varepsilon_{t}^{z}
\end{aligned}
$$

or

$$
\begin{aligned}
& \tilde{z}_{t}=\delta_{z} E_{t} \tilde{z}_{t+1}+\left(1-\delta_{z}\right) \tilde{z}_{t-1}+\hat{r}_{t}-\hat{r}_{t}^{*}+\psi_{z t}+\varepsilon_{t}^{z} \\
& \psi_{z t}=-\left(1-\delta_{z}\right) \Delta_{2} \bar{z}_{t+1}
\end{aligned}
$$

Thus the errors in each of the equations consist of the shocks plus combinations of steady state paths. This may create problems if one tries to estimate equations expressed only in terms of gaps. In the event that the steady state variables are constant then one can simply de-mean the variables before estimation. But in other cases one needs to allow for the presence of evolving steady state paths. For forecasting it is clearly the case that some paths need to be specified. If one has some quantitative values for the parameters then impulse response analysis can always be performed since the steady path values are held constant in such exercises. 


\section{REFERENCES}

Berg A., P. Karam, and D. Laxton, 2006, "Practical Model-Based Monetary Policy Analysis - A How-to Guide”, IMF Working Paper 06/81 (Washington, D.C.: International Monetary Fund).

Casares, M., and B.T. McCallum, 2006, "An Optimizing IS-LM Framework with Endogenous Investment", Journal of Macroeconomics, Vol. 28, pp 621-44.

Dungey, M., and A.R. Pagan, 2000, "A Structural VAR Model of the Australian Economy", Economic Record, Vol. 76, pp 321-42.

Gali, J., and T. Monacelli, 2005, "Monetary Policy and Exchange Rate Volatility in a Small Open Economy", Review of Economic Studies, Vol. 72, pp. 707-34.

Hostland, D., and P. Karam, 2005, "Assessing Debt Sustainability in Emerging Market Economies Using Stochastic Simulation Methods," IMF Working Paper 05/226 (Washington, D.C.: International Monetary Fund).

,2006, "Specification of a Stochastic Simulation Model for Assessing Debt Sustainability in Emerging Market Economies," IMF Working Paper 06/268 (Washington, D.C.: International Monetary Fund).

Justiniano, A., and B. Preston, 2006, "Can Structural Small Open Economy Models Account For the Influence of Foreign Disturbances", CAMA Working Paper, 2006-12.

Nimark, C., 2007, “A Structural Model of Australia as a Small Open Economy”, Reserve Bank of Australia Discussion Paper 2007-01 .

Schmitt-Grohe S., and M. Uribe, 2003, "Closing Small Open Economy Models", Journal of International Economics, Vol. 61, pp 163-85.

Smets F., and R. Wouters, 2003, "An Estimated Stochastic General Equilibrium Model of the Euro Area", European Economic Association, Vol. 1, pp. 1123-75.

Svensson L.E.O., 2000, "Open-Economy Inflation Targeting", Journal of International Economics, Vol. 50(1), pp.155-83. 